\title{
High-Level Heterologous Expression and Secretion in Rapidly Growing Nonpathogenic Mycobacteria of Four Major Mycobacterium tuberculosis Extracellular Proteins Considered To Be Leading Vaccine Candidates and Drug Targets
}

\author{
GÜNTER HARTH, BAI-YU LEE, AND MARCUS A. HORWITZ** \\ Department of Medicine, School of Medicine, University of California, Los Angeles, Los Angeles, California 90095
}

Received 23 January 1997/Returned for modification 4 March 1997/Accepted 28 March 1997

\begin{abstract}
Mycobacterium tuberculosis, the primary etiologic agent of tuberculosis, is the world's leading cause of death from a single infectious agent, and new vaccines and drugs to combat it are urgently needed. The major extracellular proteins of $M$. tuberculosis, which are released into its phagosome in macrophages, its host cells in humans, are leading candidates for a vaccine and prime targets for new drugs. However, the development of these biologicals has been hampered by the unavailability of large quantities of recombinant extracellular proteins identical to their native counterparts. In this report, we describe the heterologous expression and secretion of four major $M$. tuberculosis extracellular proteins (the 30-, 32, 16-, and 23.5-kDa proteins-the first, second, third, and eighth most abundant, respectively) in rapidly growing, nonpathogenic mycobacterial species. Multiple attempts to obtain secretion of the proteins by using Escherichia coli- and Bacillus subtilisbased expression systems were unsuccessful, suggesting that high-level expression and secretion of these Mycobacterium-specific proteins require a mycobacterial host. All four recombinant proteins were stably expressed from the cloned genes' own promoters at yields that were 5- to 10 -fold higher than those observed for the native proteins. The four proteins were purified to apparent homogeneity from culture filtrates by ammonium sulfate precipitation and ion-exchange and molecular sieve chromatography. The recombinant proteins were indistinguishable from their native counterparts by multiple criteria. First, N-terminal amino acid sequence determination demonstrated that processing of the leader peptides was highly accurate. Second, sodium dodecyl sulfate-polyacrylamide gel electrophoresis analysis revealed identical migration patterns. Third, mass spectrometry analysis confirmed that differences in mass were $\leq 5 \mathrm{Da}$. A homolog of the $M$. tuberculosis 30-kDa protein was identified in $M$. smegmatis by means of DNA analyses and immunoscreening. This is the first time that secretion of recombinant $M$. tuberculosis extracellular proteins in their native form has been achieved. This study opens the door to mass production of correctly processed and secreted extracellular proteins of $M$. tuberculosis in a heterologous host and allows ready evaluation of their biologic and immunologic function.
\end{abstract}

Tuberculosis (TB) has been declared a global emergency by the World Health Organization, the first disease so designated. The World Health Organization has estimated that 30 million people will die worldwide from TB during the next 10 years. Compounding this tragedy is the worldwide emergence of multidrug-resistant strains of Mycobacterium tuberculosis, the primary causative agent of TB. This situation has created an urgent need for a vaccine to prevent $\mathrm{TB}$ and for new drugs to combat the disease.

Extracellular proteins of $M$. tuberculosis figure prominently in new vaccine and drug development. Extracellular proteins of $M$. tuberculosis are proteins that are secreted or otherwise released by the bacterium into its extracellular milieu. The major extracellular proteins are released by $M$. tuberculosis organisms growing either extracellularly in broth culture or intracellularly within a phagosome in host mononuclear phagocytes $(8,10,12,16)$.

Purified major extracellular proteins of M. tuberculosis are leading vaccine candidates. In previous studies, we have shown that such proteins are capable of inducing protective immunity

* Corresponding author. Mailing address: Department of Medicine, School of Medicine, University of California, Los Angeles, $10833 \mathrm{Le}$ Conte Avenue, Los Angeles, CA 90095. Phone: (310) 206-0074. Fax: (310) 794-7156. against aerosol challenge with $M$. tuberculosis in the outbred guinea pig model of pulmonary tuberculosis (10). Guinea pigs are highly susceptible to TB and constitute the most relevant small animal model of TB because they develop a disease that closely mimics TB in humans (10). Purified major extracellular proteins are the only proteins and the only defined molecules yet demonstrated to induce protective immunity. Among the most promising of the major extracellular proteins as vaccine candidates are the first, second, and third most abundant, the 30 (also called antigen 85B)-, 32 (also called antigen 85A)-, and $16-\mathrm{kDa}$ proteins, respectively, and the eighth most abundant, the $23.5-\mathrm{kDa}$ protein $(8,10)$.

Major extracellular proteins are also prime targets for drug development. Many of these proteins have been found to have enzyme activity, including the $58-\mathrm{kDa}$ protein, glutamine synthetase (7); the 23-kDa protein, superoxide dismutase (25); and the 30- and 32-kDa complex of proteins, mycolyl transferase (2). We have found (7a) that selective inhibition of the extracellular enzymatic activity of one such major extracellular protein, glutamine synthetase, a protein released by pathogenic mycobacterial species but not nonpathogenic ones, inhibits M. tuberculosis multiplication both in broth culture and within human macrophages.

Because $M$. tuberculosis is both exceptionally slow growing and biohazardous, the evaluation of major extracellular pro- 
TABLE 1. Bacterial strains and plasmids used for expression studies

\begin{tabular}{|c|c|c|c|}
\hline Strain or plasmid ${ }^{a}$ & Genotype $^{d}$ & $\begin{array}{l}\text { Growth medium } \\
\text { or marker(s) }\end{array}$ & $\begin{array}{l}\text { Source or } \\
\text { reference }\end{array}$ \\
\hline \multicolumn{4}{|l|}{ E. coli } \\
\hline BL21 (DE3) pLysS & $\lambda \mathrm{DE} 3$ lysogen; $\mathrm{F}^{-}$omp $\mathrm{T}\left(\mathrm{r}_{\mathrm{B}}{ }^{-} \mathrm{m}_{\mathrm{B}}{ }^{-}\right)$ & LB broth & Novagen \\
\hline $\mathrm{DH} 5 \alpha$ & $\begin{array}{l}\mathrm{F}^{-} \text {endA1 hsdR17 }\left(\mathrm{r}_{\mathrm{K}}^{-} \mathrm{m}_{\mathrm{K}}^{+}\right) \text {supE44 thi-1 } \lambda^{-} \text {recA1 } \\
\text { gyrA96 relA1 deoR } \phi 80 \mathrm{~d} l a c Z \Delta \mathrm{M} 15 \Delta(\text { lacZYA-argF }) \mathrm{U} 169\end{array}$ & LB broth & GIBCO/BRL \\
\hline GI698 & $\mathrm{F}^{-} \lambda^{-}$lacI $^{\mathrm{q}}$ lacPL8 ampC:: $\mathrm{P}_{t r p} c \mathrm{I}$ & LB broth & Invitrogen \\
\hline GI724 & $\mathrm{F}^{-} \lambda^{-}$lacI $I^{\mathrm{q}}$ lacPL8 ampC $:: \mathrm{P}_{t r p} c \mathrm{I}$ & LB broth & Invitrogen \\
\hline JM109 & $\begin{array}{l}\mathrm{F}^{\prime}\left(\text { traD36 proAB }{ }^{+} \text {lacI } I^{\mathrm{q}} \text { lacZuM15) hsdR17 }\left(\mathrm{r}_{\mathrm{K}}{ }^{-} \mathrm{m}_{\mathrm{K}}{ }^{+}\right)\right. \\
\text {endA1recA1supE44 thi-1 gyrA96 relA1 } \Delta(\text { lac-proAB) }\end{array}$ & LB broth & Invitrogen \\
\hline B. subtilis $\mathrm{BD} 168$ & $\operatorname{trpC2}$ & VY broth & 6 \\
\hline M. smegmatis $1-2 \mathrm{c}^{b}$ & & 7H9 broth & 5 \\
\hline M. vaccae R877R-NCTC11659 & & $7 \mathrm{H} 9$ broth & 5 \\
\hline \multicolumn{4}{|l|}{ Cloning vehicles } \\
\hline pET20 & ColE1 ori; pT7 & $A m p^{r}$ & Invitrogen \\
\hline $\mathrm{pET} 22 \mathrm{~b}(+)$ & ColE1 ori; pT7 & $A m p^{r}$ & Invitrogen \\
\hline $\mathrm{pKK} 233-2^{c}$ & ColE1 ori; ptrc & $A m p^{r}$ & 1 \\
\hline pRSET-A & ColE1 ori; pT7 & $\mathrm{Amp}^{\mathrm{r}}$ & Invitrogen \\
\hline pTrxFus & ColE1 ori; pT7 & $A m p^{r}$ & Invitrogen \\
\hline pKH80 & B. subtilis-E. coli shuttle vector; peryR & $\mathrm{Amp}^{\mathrm{r}}$, Ery $^{\mathrm{r}}$, Tet $^{\mathrm{r}}$ & 6 \\
\hline pPL608 & pUB110 ori; pSPO2 & $\mathrm{Cam}^{\mathrm{r}}, \mathrm{Neo}^{\mathrm{r}}$ & 23 \\
\hline $\mathrm{pSMT}^{b}$ & Mycobacterium-E. coli shuttle vector; phsp60 & Hyg $^{\mathrm{r}}$ & 5 \\
\hline
\end{tabular}

${ }^{a}$ The following were obtained from the American Type Culture Collection: strain BD168 (ATCC 27689), plasmid pKH80 (ATCC 37093), and plasmid pPL608 (ATCC 37108).

${ }^{b}$ Provided by Peadar O'Gaora, Imperial College School of Medicine at St. Mary's, London, United Kingdom.

${ }^{c}$ Provided by Andrew Campbell, Brown University, Providence, R.I.

${ }^{d}$ Genetic markers are abbreviated as follows: ori, replication origin; peryR, erythromycin resistance gene promoter; phsp60, 60-kDa heat shock protein promoter; pSPO2, phage SPO2 promoter; pT7, bacteriophage T7 promoter; ptrc, hybrid trp-lac promoter.

${ }^{e}$ Antibiotic resistance markers are abbreviated as follows: Amp, ampicillin; Cam, chloramphenicol; Ery, erythromycin; Hyg, hygromycin; Neo, neomycin; Tet, tetracycline.

teins in a vaccine trial and as drug targets imposes a practical requirement that they be produced in recombinant form in a rapidly growing, nonpathogenic host. However, while expression of these proteins as insoluble intracellular proteins or as secreted fusion proteins has been achieved by us and others $(8$, $11,14,25)$, high-level expression and secretion of these proteins in native form have proved difficult. Indeed, we shall describe below several unsuccessful attempts to do so by using Escherichia coli and Bacillus subtilis as host cells. In this paper, we shall demonstrate for the first time the high-level expression and secretion in native form of recombinant major extracellular proteins of $M$. tuberculosis by using Mycobacterium smegmatis and Mycobacterium vaccae, two rapid growing nonpathogenic mycobacteria, as hosts. We shall also report the sequence of the genes encoding the $16-$ and the $23.5-\mathrm{kDa} M$. tuberculosis Erdman major extracellular proteins, which have not been previously reported.

\section{MATERIALS AND METHODS}

Bacterial strains and plasmids. All of the bacterial strains used in this study, their relevant genotypes and growth conditions, and all of the wild-type plasmids used for general cloning purposes are listed in Table 1. All of the recombinant plasmids assayed for expression of the 30-, 32-, 16-, and 23.5-kDa extracellular $M$. tuberculosis Erdman proteins and their relevant genetic features are listed in Table 2.

Cloning procedures and DNA analyses. The isolation of high-molecularweight genomic DNA of $M$. tuberculosis Erdman by hot-phenol extraction and the procedures for cloning and sequencing of the genes encoding the 30- and $32-\mathrm{kDa}$ proteins have already been described (8). The 16- and 23.5-kDa protein genes were cloned by PCR methodology with primer pairs 1 and 2 (for map positions of the primers on the respective genes, see Fig. 1), which were based on the N-terminal amino acid sequence of the $16-\mathrm{kDa}$ protein (10) and on the published DNA sequence of the 23.5-kDa protein (MPT64) from M. tuberculosis
H37Rv (15). The PCR products were then used to identify the corresponding genes from genomic M. tuberculosis Erdman DNA by Southern hybridization. Both genes, including extensive flanking regions, were cloned into pUC19 (24). The coding regions for the 30 - and $32-\mathrm{kDa}$ proteins are $\sim 1 \mathrm{kbp}$ long and are contained within an $\sim 4.7-\mathrm{kbp}$ HindIII-Bam HI genomic restriction fragment (30kDa protein) or within an $\sim 4.5 \mathrm{kbp} E c o$ RV genomic DNA fragment (32-kDa protein), both of which were completely sequenced by the chain termination method (18). The coding region for the $16-\mathrm{kDa}$ protein is $\sim 0.5 \mathrm{~kb}$ long and is contained within an $\sim 5.5 \mathrm{kbp} \mathrm{BamHI}$ restriction fragment whose DNA sequence was also completely determined. The coding region for the $23.5-\mathrm{kDa}$ protein is $\sim 0.7 \mathrm{~kb}$ long and is contained within an $\sim 9.5-\mathrm{kbp}$ Bam HI genomic restriction fragment. This DNA fragment was not completely sequenced; rather, after establishing the DNA sequence of the region encoding the $23.5-\mathrm{kDa}$ protein, we extended the sequence analysis into the $5^{\prime}$ and $3^{\prime}$ flanking regions and used this information to amplify and clone a stretch of $\sim 1.5 \mathrm{kbp}$, encompassing the $23.5-\mathrm{kDa}$ protein gene, into pUC19. All DNA sequences were analyzed by the GCG sequence analysis software package, version 7, from the University of Wisconsin, Madison.

All recombinant constructs assayed for expression of the 30-, 32-, 16-, and $23.5-\mathrm{kD}$ a proteins were derived from the original, recombinant pUC19 plasmids by direct subcloning of internal restriction fragments or by generating an amplification product flanked by restriction enzyme sites to allow directional ligation of the structural genes encoding either the mature or the full-length protein into the appropriate expression vector sites as listed in Table 2. Constructs in pSMT3 were established in E. coli DH5 $\alpha$ and then electroporated into M. smegmatis 1-2c as previously described (5). For each construct, at least two clones were characterized by restriction enzyme mapping and DNA sequence analysis.

Purification and characterization of recombinant 30-, 32-, 16-, and 23.5-kDa proteins. Expression of recombinant proteins was initially monitored by taking samples of the bacterial cultures at various time points (hourly for up to $8 \mathrm{~h}$ after induction for the E. coli and B. subtilis strains and every $12 \mathrm{~h}$ for up to 3 days for the $M$. smegmatis 1-2c cultures), separating culture filtrates and cell pellets by centrifugation and filtration, and analyzing the two fractions on $12.5 \%$ denaturing polyacrylamide gels (National Diagnostics). Subsequently, cultures were grown for a period of time at which expression of recombinant proteins was maximal. Extracellular and cell-associated recombinant proteins expressed in $M$. smegmatis $1-2 \mathrm{c}$ cultures were purified as previously described (10) and charac- 
TABLE 2. Constructs used to assay for expression of recombinant M. tuberculosis 30-, 32-, 16-, 23.5-kDa proteins

\begin{tabular}{|c|c|c|c|c|c|c|}
\hline Protein and plasmid ${ }^{a}$ & Host strain & Insert $^{b}$ & Expression $^{c}$ & Secretion $^{c}$ & $\begin{array}{l}\% \text { Mature } \\
\text { protein }^{d}\end{array}$ & $\begin{array}{c}\text { Yield (mg/liter) } \\
\text { of purified } \\
\text { protein }\end{array}$ \\
\hline \multicolumn{7}{|l|}{$30 \mathrm{kDa}$} \\
\hline pET20 & E. coli BL21 & M 30 kDa; 0.85 kb (PCR); NdeI/EcoRI; $\rightarrow$ & - & - & & \\
\hline pET22b(+) & E. coli BL21 & FL 30 kDa; 0.98 kb (PCR); NdeI/EcoRI; $\rightarrow$ & + (fusion) & - & $40(+2$ aа $)$ & 1 \\
\hline pKK233-2 & E. coli JM109 & M 30 kDa; 0.85 kb (PCR); NcoI/HindIII; $\rightarrow$ & - & - & & \\
\hline pRSET-A & E. coli BL21 & M 30 kDa; 0.85 kb (PCR); BamHI/EcoRI; $\rightarrow$ & + (fusion) & - & $10(+2 \mathrm{aa})$ & $<1$ \\
\hline pTrxFus & E. coli GI724/698 & M 30 kDa; 0.85 kb (PCR); KpnI/BamHI; $\rightarrow$ & + (fusion) & - & $10(+2 \mathrm{aa})$ & $<1$ \\
\hline pKH80 & B. subtilis BD168 & M 30 kDa; 0.85 kb (PCR); BclI; $\rightarrow$ & - & - & & \\
\hline pSMT3* & M. smegmatis $1-2 c$ & FL 30 kDa; 4.7 kb (gene); HindIII/BamHI; $\leftarrow$ & + & + & 95 & 2.5 \\
\hline pSMT3* & M. vaccae $\mathrm{R} 877 \mathrm{R}$ & FL $30 \mathrm{kDa} ; 4.7 \mathrm{~kb}$ (gene); HindIII/BamHI; $\leftarrow$ & + & + & 95 & 2.5 \\
\hline \multicolumn{7}{|l|}{$32 \mathrm{kDa}$} \\
\hline pET20 & E. coli BL21 & M 32 kDa; 0.9 kb (PCR); NdeI/EcoRI; $\rightarrow$ & - & - & & \\
\hline pET22b(+) & E. coli BL21 & FL $32 \mathrm{kDa} ; 1.25 \mathrm{~kb}$ (PCR); NdeI/EcoRI; $\rightarrow$ & + & - & $90(+2$ аa) & 1 \\
\hline pKK233-2 & E. coli JM109 & FL 32 kDa; $1.25 \mathrm{~kb}$ (PCR); NcoI/HindIII; $\rightarrow$ & - & - & & \\
\hline pPL608 & B. subtilis BD168 & FL 32 kDa; 0.9 kb (PCR); SmaI/HincII; $\rightarrow$ & - & - & & \\
\hline pSMT3 & M. smegmatis $1-2 \mathrm{c}$ & FL $32 \mathrm{kDa} ; 4.5 \mathrm{~kb}$ (gene); EcoRV; $\rightarrow$ & $+\left(28^{\circ} \mathrm{C}\right)$ & + & & \\
\hline pSMT3 & M. smegmatis $1-2 \mathrm{c}$ & FL $32 \mathrm{kDa} ; 4.5 \mathrm{~kb}$ (gene); EcoRV; $\leftarrow$ & $+\left(28^{\circ} \mathrm{C}\right)$ & + & 95 & \\
\hline pSMT3 & M. smegmatis $1-2 \mathrm{c}$ & FL 32 kDa; 1.5 kb (PCR); BamHI; $\rightarrow$ & - & - & & \\
\hline pSMT3* & M. smegmatis $1-2 \mathrm{c}$ & FL $32 \mathrm{kDa} ; 1.5 \mathrm{~kb}$ (PCR); BamHI; $\leftarrow$ & $+\left(28^{\circ} \mathrm{C}\right)$ & + & 99 & 2.5 \\
\hline pSMT3 & M. smegmatis $1-2 \mathrm{c}$ & FL 32 kDa; 1.25 kb (PCR); BamHI; $\rightarrow$ & - & - & & \\
\hline pSMT3 & M. smegmatis $1-2 \mathrm{c}$ & FL 32 kDa; $1.25 \mathrm{~kb}$ (PCR); BamHI; $\leftarrow$ & $+\left(\right.$ fusion; $\left.28^{\circ} \mathrm{C}\right)$ & + & 90 & \\
\hline pSMT3 & M. vaccae $\mathrm{R} 877 \mathrm{R}$ & FL $32 \mathrm{kDa} ; 4.5 \mathrm{~kb}$ (gene); EcoRV; $\rightarrow$ & + & $+(10 \%)$ & & \\
\hline pSMT3 & M. vaccae $\mathrm{R} 877 \mathrm{R}$ & FL $32 \mathrm{kDa} ; 4.5 \mathrm{~kb}$ (gene); EcoRV; $\leftarrow$ & - & - & & \\
\hline \multicolumn{7}{|l|}{$16 \mathrm{kDa}$} \\
\hline pSMT3* & M. smegmatis $1-2 \mathrm{c}$ & FL 16 kDa; 5.5 kb (gene); BamHI; $\leftarrow$ & + & + & 99 & 2.5 \\
\hline pSMT3* & M. vaccae $\mathrm{R} 877 \mathrm{R}$ & FL 16 kDa; 5.5 kb (gene); BamHI; $\leftarrow$ & + & + & 99 & 2.5 \\
\hline \multicolumn{7}{|l|}{$23.5 \mathrm{kDa}$} \\
\hline pSMT3* & M. smegmatis $1-2 \mathrm{c}$ & FL 23.5 kDa; 1.4 kb (PCR); BamHI; $\rightarrow$ & + & + & 99 & 7.5 \\
\hline
\end{tabular}

${ }^{a}$ Constructs described in the text are in boldface. For information on plasmids and host strains, see Table 1. Plasmids marked with asterisks were designated pMTB30, pMTB32A, pMTB16, and pMTB23.5 for the 30-, 32-, 16-, and 23.5-kDa proteins, respectively.

${ }^{b}$ The description of each insert includes (i) the designation of the structural gene according to the protein encoded, preceded by the letters FL to indicate that the gene encodes the full-length protein, including the leader peptide, or the letter $\mathrm{M}$ to indicate that the gene encodes only the mature protein; (ii) the size of the insert followed, in parentheses, by the word "gene" to indicate that the insert is the original genomic locus or by the abbreviation "PCR" to indicate that the insert is an amplification product of the original genomic locus; (iii) the restriction enzyme site(s) at the vector-insert junction(s); and (iv) the orientation of the insert with regard to the plasmid-encoded promoter of heat shock protein 60 .

${ }^{c}$ Expression and secretion of the proteins are indicated by a plus sign, and lack thereof is indicated by a minus sign. Expression of a fusion protein and/or expression only at $28^{\circ} \mathrm{C}$ is indicated in parentheses in the Expression column. Fusion proteins contain vector-encoded amino acids (between the cloning site and the first ATG) at their $\mathrm{N}$ termini. Limitation of secretion to a minority of the expressed protein is indicated in parentheses in the Secretion column.

${ }^{d} \mathrm{~N}$ termini of mature proteins were determined by amino acid sequence analysis; +2 aa indicates that the mature protein contains two additional $\mathrm{N}$-terminal amino acids.

terized by N-terminal amino acid sequencing (performed at the UCLA Protein Microsequencing Facility) and immunoblotting.

Identification of homologs. The search for homologs to the four M. tuberculosis Erdman genes in M. smegmatis 1-2c was performed by gene amplification, DNA hybridization, and immunoblotting.

(i) Gene amplification. PCR-based analyses to detect homologs of the $M$. tuberculosis 30-, 32-, 16-, and 23.5-kDa protein genes in M. smegmatis used primers 1 and 2 for the 30-, 32-, and 23.5-kDa protein genes and primers 3 and 4 for the 16-kDa protein (Fig. 1) for 40 rounds of amplification at 94, 42, and $70^{\circ} \mathrm{C}$ with $1 \mu \mathrm{g}$ of genomic M. tuberculosis and M. smegmatis DNA and 1 to $2 \mathrm{U}$ of Taq DNA polymerase (Fisher, Perkin Elmer). All PCR products were analyzed by agarose gel electrophoresis and visualized by UV transillumination.

(ii) DNA hybridization. Southern DNA hybridizations were performed by using $\sim 5 \mu \mathrm{g}$ of genomic $M$. tuberculosis and $M$. smegmatis DNA and oligonucleotide probes (primer 3 for the 30- and 32-kDa protein genes, primers 3 and 4 for the $16-\mathrm{kDa}$ protein gene, and primers 1 and 2 for the $23.5-\mathrm{kDa}$ protein gene) radiolabelled to $\sim 5 \times 10^{7}$ to $1 \times 10^{8} \mathrm{cpm} / \mu \mathrm{g}$. Nitrocellulose filters were kept overnight at 50 or $42^{\circ} \mathrm{C}$ in $5 \times \mathrm{SSC}(1 \times \mathrm{SSC}$ is $150 \mathrm{mM} \mathrm{NaCl}$ plus $15 \mathrm{mM} \mathrm{Na}$ citrate) or in Church hybridization buffer (500 mM Na phosphate [pH 7.2], 7\% sodium dodecyl sulfate, $1 \mathrm{mM}$ EDTA [3]) and subsequently washed, dried, and autoradiographed on Kodak X-Omat AR5 film for 48 to $72 \mathrm{~h}$ at $-70^{\circ} \mathrm{C}$ with a Cronex Lightning-Plus intensifying screen (Du Pont).

(iii) Immunoblotting. Culture filtrates and cell pellets of axenically grown $M$. tuberculosis Erdman and M. smegmatis 1-2c were prepared and electrophoresed as described above, transferred to nitrocellulose membranes, and probed with antibodies (diluted 1:5,000) specific for the $30 / 32-\mathrm{kDa}$ protein complex, the $16-\mathrm{kDa}$ protein, or the $23.5-\mathrm{kDa}$ protein. The antibodies were generated in rabbits, had reciprocal titers between 2,500 and 10,000, and were shown to recognize native and denatured forms of the four proteins equally well. Following incubation with alkaline phosphatase-conjugated goat anti-rabbit antibodies, proteins were visualized by staining with alkaline phosphatase-specific color development reagents (Bio-Rad).

Reagents and enzymes. All chemicals were purchased from Sigma unless indicated otherwise and were of the highest grade possible. Enzymes were purchased from either New England Biolabs, Fisher/Promega, or Appligene. Oligonucleotides for amplification reactions and DNA sequencing were purchased from either BioSynthesis or GIBCO/BRL, and radiolabelled nucleotides were obtained from Amersham or New England Nuclear.

Nucleotide sequence accession numbers. The nucleotide sequences of the four genes examined in this study are available from GenBank under accession numbers MTB30-8 U38939 (30-kDa protein gene), MTB32-2 U47335 (32-kDa protein gene), U82234 (16-kDa protein gene), and U82235 (23.5-kDa protein gene).

\section{RESULTS}

Determination of the DNA sequences encoding the 30-, 32-, 16-, and 23.5-kDa proteins and their genetic loci. We have previously reported the cloning and sequencing of the genes encoding the $30-$ and $32-\mathrm{kDa}$ proteins, including extensive flanking DNA sequences (8). The DNA fragments containing the genes for the $16-$ and $23.5-\mathrm{kDa}$ proteins and extensive flanking regions were isolated from high-molecular-weight 


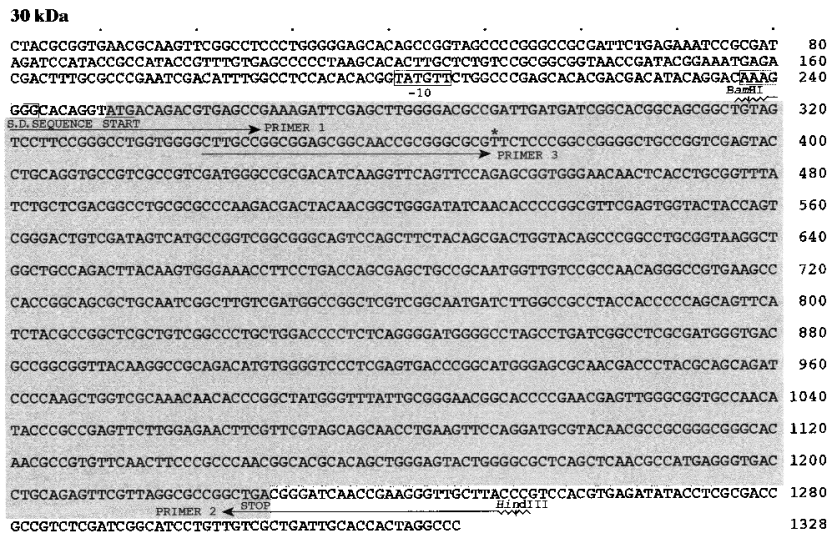

$32 \mathrm{kDa}$

GACCCGGCACTAGCGGTCGACACATGCCCAGACACTGCGGAAATGCCACCTTCAGGCCGTCGCGTCGGTCCCGAATTGGC ACTGCCGGGCCCAGCGCCTGCAGTCTGACCTAATTCAGGATGCGCCCAAACATGCATGGATGCGTTGAGATGAGGATGAG GGAAGCAAGAATGCAGCTTGTTGACAGGGTTCGTGGCGCCGTCACGGGTATGTCGCGTCGACTCGTGGTCGGGGCCGTCG GCGCGGCCCTAGTGTCGGGTCTGGTCGGCGCCGTCGETTGCCACGGCGACCGCGGGGGCANTTTTCCCGGCCGGGCTTGCCG 40 GTGGAGTACCTGCAGGTGCCGTCGCCGTCGATGGGCCGTGACATCAAGGTCCAATTCCAAAGTGGTGGTGCCAACTCGCC CGCCCTGTACCTGCTCGACGGCCTGCGCGCGCAGGACGACTTCAGCGGCTGGGACATCAACACCCCGGCGTTCGAGTGGT ACGACCAGTCGGGCCTGTCGGTGGTCATGCCGGTGGGTGGCCAGTCAAGCTTCTACTCCGACTGGTACCAGCCCGCCTGC GGCAAGGCCGGTTGCCAGACTTACAAGTGGGAGACCTTCCTGACCAGCGAGCTGCCGGGGTGGCTGCAGGCCAACAGGCA CGTCAAGCCCACCGGAAGCGCCGTCGTCGGTCTITCGATGGCTGCTTCTTCGGCGCTGACGCTGGCGATCTATCACCCCC AGCAGTTCGTCTACGCGGGAGCGATGTCGGGCCTGTTGGACCCCTCCCAGGCGATGGGTCCCACCCTGATCGGCCTGGCG ATGGGTGACGCTGGCGGCTACAAGGCCTCCGACATGTGGGGCCCGAAGGAGGACCCGGCGTGGCAGCGCAACGACCCGCT 960 GTTGAACGTCGGGAAGCTGATCGCCAACAACACCCGCGTCTGGGTGTACTGCGGCAACGGCAAGCCGTCGGATCTGGGTG 1040 GCAACAACCTGCCGGCCAAGTTCCTCGAGGGCTTCGTGCGGACCAGCAACATCAAGTTCCAAGACGCCTACAACGCCGGT 1120 GGCGGCCACAACGGCGTGTTCGACTTCCCGGACAGCGGTACGCACAGCTGGGAGTACTGGGGCGCGCAGCTCAACGCTAT 1200 GAAGCCCGACCTGCAACGGGCACTGGGTGCCACGCCAACACCGGGCCCGCGCCCCAGGGCGCCTACCTCCGAACAGACA 1280 CAACATCTAGCGGCGGTGACCCTTGTGGTCGCCGCCGCTAGATGTTTCCTAAATCCCGTCCCTAGCTCCCGCCGCGGGCC 1360 GTGTGGT

$16 \mathrm{kDa}$

GGGTATGGCGGTCACCACACCATCCTEACATGCGGTTTGGCTCCCTTGCGCTGGTCGCCTACGACHCGGCCATCAAGCA

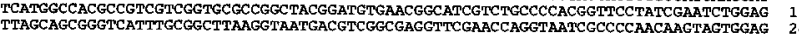
GIAGGGACCAATGAAGCTCACCACAATGATCAAGACGGCAGTAGCGGTCGTGGCCATGGCGGCCATCGCGACCTTTTCCGG 32

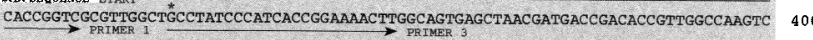
$\underset{\text { GTGCTCGGCTGGAAGGTCAGTGATCTCAAATCCAGCACGGCAGTCATCCCCGGCTATCCGGTGGCCGGCCAGGTCTGGGA }}{\longrightarrow}$ GGCCACTGCCACGGTCAATGCGATTCGCGGCAGCGTCACGCCCGCGGTCTCGCAGTTCAATGCCCGCACCGCCGACGGCA 560 TCAACTACCGGGTGCTGTGGCAAGCCGCGGGCCCCGACACCATTAGCGGAGCCACTATCCCCCAAGGCGAACAATCGACC 640 GGCAAAATCTACTTCGATGTCACCGGCCCATCGCCAACCATCGTCGCGATGAACAACGGCATGGAGGATCTGCTGATTTG 720 GGAGCCGTAGATCGTAGCTAATGCACGCCCAGGCGACCGCTGAGGTATTGGGCGCGGCAGGCCTGGCGAGCCAGCTTCCC 80 GCTGGTGGTGCGTGGAAIGGCGCCGGCCGC

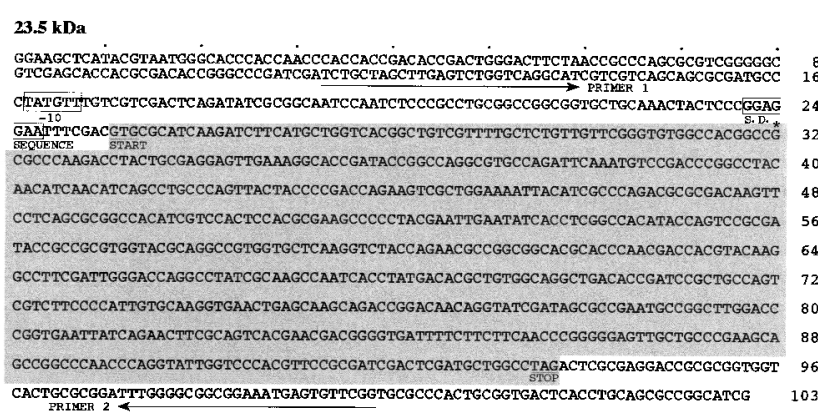

FIG. 1. DNA sequences of the 30-, 32-, 16-, and 23.5-kDa protein genes. The sequences show the $5^{\prime}$ to $3^{\prime}$ sense DNA strands of the four structural genes (shaded box). The initiator methionine codons of the genes are underlined and marked START. The first codon of each mature protein is indicated by an asterisk. The termination codons are underlined and marked STOP. The structural genes are flanked by 250 nucleotides at the $5^{\prime}$ end and 100 nucleotides at the $3^{\prime}$ end (unshaded). Sequences are further annotated by boxes matching Shine-Dalgarno sequences (S.D. SEQUENCE) and boxes indicating tentatively assigned -10 and -35 promoter elements. Furthermore, the map positions of genomic $M$. tuberculosis Erdman DNA by PCR methodology and Southern hybridization. Figure 1 shows the DNA sequences of the coding strands in $5^{\prime}$ to $3^{\prime}$ direction for the four protein genes plus the $250 \mathrm{bp}$ upstream and the $100 \mathrm{bp}$ downstream of the structural genes.

The genetic loci for three of the four genes are known. The $30-\mathrm{kDa}$ protein (also designated $\mathrm{FbpB}$ ) gene maps to cosmid Y207, the 32-kDa protein (also designated $\mathrm{FbpA}$ ) gene maps to cosmids Y430 and Y302, and the $23.5-\mathrm{kDa}$ protein (also designated MPT64) gene maps near the 3' end of cosmid Y39. No map position has been described for the $16-\mathrm{kDa}$ protein gene, although a homology search, using the entire DNA sequence of the 5.5-kb BamHI DNA fragment containing the 16-kDa protein gene, shows limited sequence identity with cosmid tbc2 (17).

Analysis of DNA sequences flanking the structural genes of the 30-, 32-, 16-, and $23.5-\mathrm{kDa}$ proteins. (i) $\mathrm{G}+\mathrm{C}$ content. As with most protein-coding genes of $M$. tuberculosis, the overall $\mathrm{G}+\mathrm{C}$ content of the genes encoding the 30-, 32-, 16-, and $23.5-\mathrm{kDa}$ proteins, including their leader peptides, is $\sim 65 \%$ and the codon usage is very similar to that described for mycobacteriophage L5 (9).

(ii) Leader peptides. All four proteins are preceded by leader peptides rich in hydrophobic amino acids; the hydrophobicity ranges from 65 to $75 \%$. The lengths of the leader peptides vary greatly -40 amino acids for the $30-\mathrm{kDa}$ protein, 43 amino acids for the $32-\mathrm{kDa}$ protein, most likely 29 amino acids for the $16-\mathrm{kDa}$ protein, and 23 amino acids for the 23.5$\mathrm{kDa}$ protein. The start site of the leader peptide for the $16-\mathrm{kDa}$ protein is uncertain, since the DNA sequence upstream of the mature protein contains three in-frame methionine codons (Fig. 1). However, only the methionine codon at position -29 with regard to the alanine residue in the +1 position of the mature protein is preceded by a strong Shine-Dalgarno sequence, GGAGG, 14 bp upstream of the ATG codon (20).

The start site of the leader peptide for the 23.5-kDa protein is also uncertain (Fig. 1). The GTG methionine codon 23 amino acids upstream of the first residue of the mature protein, alanine, is preceded $14 \mathrm{bp}$ upstream by a stronger ShineDalgarno sequence (GGAGGAA) than the in-frame ATG methionine codon 17 amino acids upstream of the start of the mature protein, which is preceded 9 bp upstream by AAGA. Interestingly, the leader peptide of the $23.5-\mathrm{kDa}$ protein contains two tandemly arranged cysteine residues, which are infrequently found in leader peptides. The site of leader peptide cleavage was determined by sequencing the $\mathrm{N}$ termini of several preparations of each of the four proteins. In each case, both the -1 and -3 positions are occupied by alanine residues, consistent with the von Heijne rule for prokaryotic leader peptides (21).

(iii) Promoter elements. Apart from the Shine-Dalgarno motif present within 20 bp upstream of each of the four structural genes, the $5^{\prime}$ flanking regions are devoid of extended domains of DNA sequence similarity. Moreover, standard $E$. coli-type promoter elements are not present within $250 \mathrm{bp}$ upstream of the structural genes (13). Based on mRNA and primer extension analyses, we previously described the motif TATGTT -47 bp upstream of the $30-\mathrm{kDa}$ protein gene as a potential candidate for the -10 promoter element (8). Other

the primers used for PCR amplifications and Southern blot analyses are indicated by arrows. Wavy lines at the $5^{\prime}$ ends of primers indicate 10 nucleotides consisting of 4 randomly selected nucleotides followed by 6 nucleotides specifying the recognition site of the restriction enzyme appearing as a superscript. 
investigators have described promoter elements upstream of the $32-\mathrm{kDa}$ protein gene and shown that, despite their apparent similarity at the DNA and protein levels, the genes encoding the 30 - and $32-\mathrm{kDa}$ proteins do not have any regulatory elements in common in their $5^{\prime}$ flanking regions (11). The transcriptional start sites for the $16-$ and $23.5-\mathrm{kDa}$ protein genes have not been mapped. The DNA sequences upstream of the $16-\mathrm{kDa}$ protein gene show very little similarity to the upstream sequences of the other three genes. Interestingly, the aforementioned -10 promoter element of the $30-\mathrm{kDa}$ protein gene is also found $\sim 87$ bp upstream of the $23.5-\mathrm{kDa}$ protein gene but there is no apparent similarity with regard to a potential -35 promoter element.

(iv) Transcription units. The genes encoding the 30 - and 32-kDa proteins apparently represent single transcription units $(8,11)$. Transcript analyses of the $16-$ and $23.5-\mathrm{kDa}$ protein genes have not been performed. The DNA sequences of the $3^{\prime}$ flanking regions of the four genes differ greatly, and none of the typical transcription termination elements described for $E$. coli mRNA, such as extensive hairpin loops and runs of five or six uracil residues (4), or other consensus elements have been identified.

Description of constructs used to express recombinant 30-, 32-, 16-, and 23.5-kDa proteins. We first focused on optimizing the expression of the two most abundant extracellular proteins, the 30- and 32-kDa proteins. As seen in Tables 1 and 2, while expression and leader peptide processing of these two proteins are possible in an E. coli-based expression system, the yield of soluble, correctly processed recombinant protein is far greater in the two mycobacterial systems used-M. smegmatis $1-2 \mathrm{c}$ and $M$. vaccae $\mathrm{R} 877 \mathrm{R}$. The fact that the mycobacterial systems allowed the use of DNA inserts in the mycobacterium- $E$. coli shuttle vector pSMT3 that were much larger than the actual genes encoding these two $M$. tuberculosis proteins suggests that the mycobacterial transcription apparatus recognized and utilized the proper promoter elements upstream of the structural genes and that the mycobacterial secretion machinery very efficiently released the processed proteins into the extracellular milieu. Since the two mycobacterial systems proved highly successful for expression of the 30- and 32-kDa proteins, we also subcloned the genes for the 16- and $23.5-\mathrm{kDa}$ proteins in this vector. The resulting recombinant plasmids were designated pMTB30, pMTB32A, pMTB16, and pMTB23.5, respectively (Table 2).

Several important issues remain unresolved. First, we do not know why constructs containing the $32-\mathrm{kDa}$ protein gene express recombinant protein only when inserted in one orientation, although the DNA insert can be cloned and stably maintained in both orientations. Second, we do not know why expression of the $32-\mathrm{kDa}$ protein is optimal at $28^{\circ} \mathrm{C}$ and dramatically decreases at $37^{\circ} \mathrm{C}$, a temperature at which the other recombinant proteins are produced in abundance. Finally, we do not know why the M. tuberculosis $23.5-\mathrm{kDa}$ DNA insert can be cloned and stably maintained in recombinant pSMT3 constructs in only one orientation with respect to the plasmidencoded promoter for the mycobacterial $60-\mathrm{kDa}$ heat shock protein.

Analysis of expression of recombinant proteins in $M$. smegmatis 1-2c. As discussed above, the mycobacterial expression systems proved far superior to the $E$. coli-based systems with regard to yield, accuracy, and efficiency of leader peptide processing and extracellular release of the four recombinant $M$. tuberculosis proteins. Since we observed no significant differences between $M$. smegmatis $1-2 \mathrm{c}$ and $M$. vaccae $\mathrm{R} 877 \mathrm{R}$ in the expression levels of the four recombinant proteins, we selected one of these expression systems, $M$. smegmatis 1-2c, for studies aimed at optimizing expression of the recombinant proteins.

We initially investigated expression of the recombinant proteins during different phases of growth of the bacteria, from the early log phase $\left(\sim 2.5 \times 10^{6}\right.$ cells per $\left.\mathrm{ml}\right)$ to the stationary phase $\left(\sim 2.5 \times 10^{9}\right.$ to $5 \times 10^{9}$ cells per $\left.\mathrm{ml}\right)$, occurring after 3 days of growth at $37^{\circ} \mathrm{C}$ (except for cultures expressing the $32-\mathrm{kDa}$ protein, which were grown at $28^{\circ} \mathrm{C}$ ). The observed yields of each of the four expressed and released recombinant proteins were strictly dependent on the total cell mass and increased in parallel with the bacterial growth curve. Bacteria expressing a recombinant $30-, 16-$, or $23.5-\mathrm{kDa}$ protein could even be held at the stationary phase for 1 to 2 days with no detectable loss or degradation of the released recombinant protein. Growth of bacteria expressing the recombinant 32$\mathrm{kDa}$ protein was slower at the lower growth temperature of $28^{\circ} \mathrm{C}$; however, the yield of expressed and released $32-\mathrm{kDa}$ protein was comparable to that of the $30-\mathrm{kDa}$ protein, provided the cultures were harvested at the late logarithmic phase.

The constitutive expression of all four recombinant proteins did not lead to intracellular accumulation of these proteins. The secretion machinery was apparently able to keep pace with protein expression and very efficiently released large quantities of the recombinant proteins into the culture medium. For each of the four proteins, the amount of expressed protein that remained in the intracellular milieu never exceeded $10 \%$.

Purification of extracellular recombinant 30-, 32-, 16-, and 23.5-kDa proteins. The recombinant proteins were isolated from $M$. smegmatis $1-2 \mathrm{c}$ culture filtrates by ammonium sulfate precipitation and purified by ion-exchange and molecular sieve chromatography as described for the native proteins (10). All purified proteins remained soluble in aqueous buffers and did not show even trace contamination with other proteins by sodium dodecyl sulfate-polyacrylamide gel electrophoresis analysis. Each preparation was essentially free of endotoxin as determined by the Limulus amoebocyte lysate assay $(<0.025$ endotoxin $\mathrm{U} / \mathrm{mg}$ or $<5 \mathrm{pg}$ of endotoxin $/ \mathrm{mg}$ ).

Purified recombinant proteins were analyzed by four techniques, the results of which are presented in Fig. 2. (i) $\mathrm{N}$ terminal amino acid sequence determination demonstrated that $>95$ to $99 \%$ of the released recombinant proteins had an $\mathrm{N}$-terminal amino acid sequence identical to that of the native molecule. Where different processing of the released recombinant proteins was observed, it involved removal of the leader peptide plus the first amino acid or second two amino acids of the mature protein. (ii) Sodium dodecyl sulfate-polyacrylamide gel electrophoresis analysis showed that each recombinant protein migrated at the same rate as its native protein counterpart. (iii) Mass spectrometry analysis of purified recombinant and native proteins revealed that both the recombinant and native proteins in a pair had the same mass $( \pm 5 \mathrm{Da})$ and were virtually indistinguishable. (iv) Immunoblot analyses showed that the recombinant proteins reacted as strongly as the native proteins with antibodies raised in rabbits against the relevant purified native $M$. tuberculosis protein.

Identification of homologs of the 30-, 32-, 16-, and 23.5-kDa protein genes and gene products in $M$. smegmatis 1-2c. A survey of the literature revealed only one report of an $M$. smegmatis protein related to one of the four $M$. tuberculosis proteins described in this study (19). This was an $\sim 25,000-\mathrm{kDa}$ mycolic acid exchange enzyme, most likely representing the homolog of the $30-\mathrm{kDa}$ protein of $M$. tuberculosis, which is also associated with mycolic acid transferase activity (2). We extended these studies by probing for the potential presence of the aforementioned four genes or their encoded proteins in M. smegmatis by 


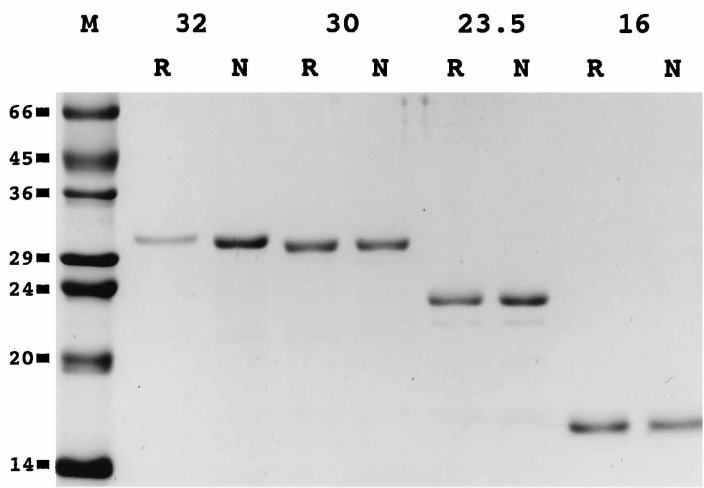

COOMASSIE

\section{RECOMBINANT \\ PROTEINS}

323023.516

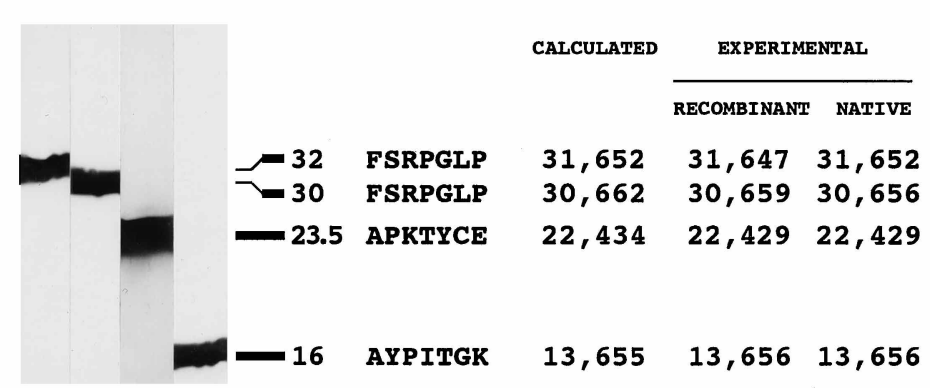

FIG. 2. Purified recombinant and native 32-, 30-, 23.5-, and 16-kDa proteins. On the left are Coomassie blue R-stained, purified recombinant and native proteins, including molecular mass standards (lane M) in kilodaltons. In the center are recombinant proteins stained with antibodies specifically raised against each individual purified native protein. On the right is a characterization of each of the proteins by its $\mathrm{N}$ terminus, calculated molecular mass (based on the DNA sequence of the structural gene), and experimentally determined molecular mass (based on mass spectrometry analysis of the native and recombinant proteins). Mass spectrometry analyses were performed by Diane Wong and Bradford Gibson at the University of California, San Francisco.

three different approaches, the results of which are presented in Fig. 3.

(i) Gene amplification. UV visualization of amplification products by using denatured genomic $M$. tuberculosis Erdman and $M$. smegmatis 1-2c DNAs and oligonucleotide primers 1 and 2 for the 30-, 32-, and 23.5-kDa protein genes and primers 3 and 4 for the $16-\mathrm{kDa}$ protein gene, revealed strong and specific bands for each of the four genes in M. tuberculosis DNA. Each band was of the expected size, $\sim 1 \mathrm{kbp}$ for each of the 30 - and $32-\mathrm{kDa}$ protein genes, $\sim 0.5 \mathrm{kbp}$ for the $16-\mathrm{kDa}$ protein gene, and $\sim 0.7 \mathrm{kbp}$ for the $23.5-\mathrm{kDa}$ protein gene.
Primers specific for the $30-\mathrm{kDa}$ protein gene yielded an amplification product in $M$. smegmatis DNA that was slightly less than $1 \mathrm{kbp}$. However, no amplification products were detected with the primer pairs specific for the $32-, 16-$, and $23.5-\mathrm{kDa}$ proteins.

(ii) DNA hybridization. All four gene-specific oligonucleotides (specified in Materials and Methods) detected unique $M$. tuberculosis restriction fragments. However, again, only the probe specific for the $30-\mathrm{kDa}$ protein gene hybridized to a unique $M$. smegmatis $1-2 \mathrm{c}$ restriction fragment (data not shown).
DNA AMPLIFICATION PRODUCTS

\section{TUBERCULOSIS}

M. SMEGMATIS

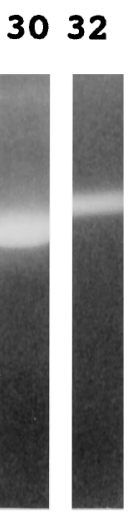

$3032 \quad 16 \quad 23.5$

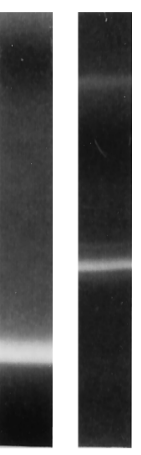

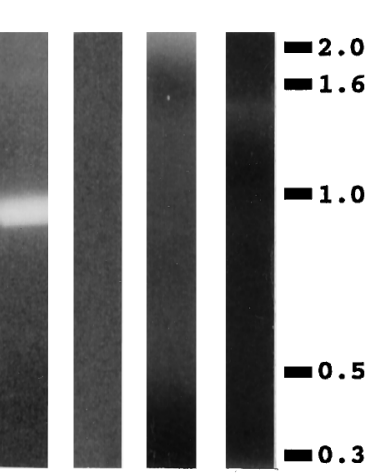

\section{IMMUNOBLOT}

\section{SMEGMATIS}

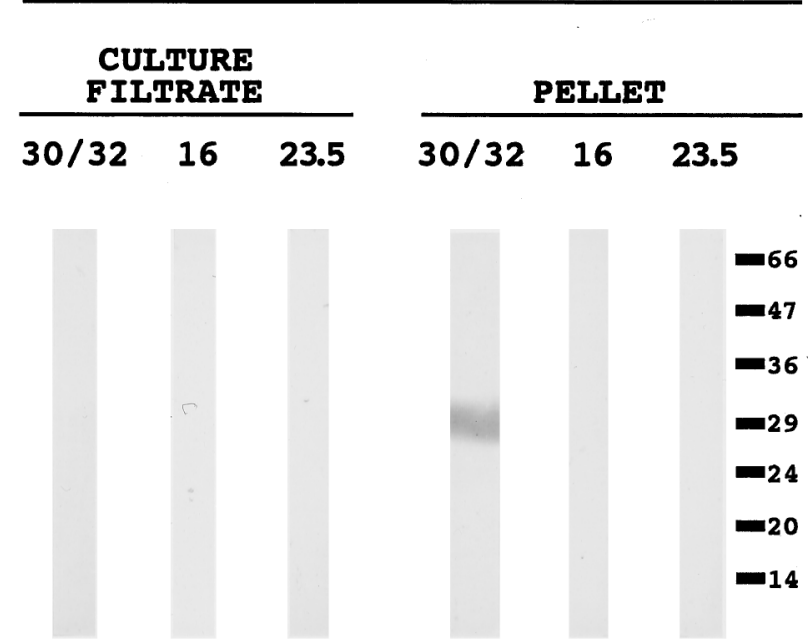

FIG. 3. Search for homologs of the M. tuberculosis 30-, 32-, 16-, and 23.5-kDa proteins in M. smegmatis. On the left are DNA amplification products of the 30-, 32-, 16-, and 23.5-kDa protein genes in M. tuberculosis Erdman and M. smegmatis 1-2c. The amplification primers used are described in Materials and Methods. Marker sizes are indicated on the right in kilobase pairs. On the right are immunoblots of extracellular (CULTURE FILTRATE) and cell-associated (PELLET) fractions of M. smegmatis probed with antibodies to the four proteins. Molecular mass standards are indicated on the right in kilodaltons. 
(iii) Immunoblotting. Antibodies specific to the $30 / 32-\mathrm{kDa}$ protein complex, the $16-\mathrm{kDa}$ protein, or the $23.5-\mathrm{kDa}$ protein reacted exclusively with their cognate antigens in both the extracellular and cell-associated fractions of M. tuberculosis; reaction with the extracellular fraction was substantially stronger (data not shown). In contrast, only an antibody specific for the $30 / 32-\mathrm{kDa}$ protein complex reacted with its cognate antigen in M. smegmatis, and then only with the cell-associated fraction. The antibodies did not recognize any extracellular $M$. smegmatis proteins.

The results from these three approaches indicate that while there is a counterpart of the $30-\mathrm{kDa}$ protein in M. smegmatis, the 32-, 16-, and 23.5-kDa proteins are specific for M. tuberculosis.

\section{DISCUSSION}

This study demonstrates the high-level expression and secretion of recombinant $M$. tuberculosis major extracellular proteins in a form indistinguishable from that of the native proteins. The host species used, $M$. smegmatis and $M$. vaccae, are nonpathogenic, grow 10 times faster than M. tuberculosis, and produce 5 to 10 times as much extracellular protein per liter as M. tuberculosis, effectively a 50- to 100-fold increase in yield per unit of time.

Repeated attempts to obtain high-level expression and secretion in E. coli were unsuccessful, prompting us first to evaluate expression systems in B. subtilis, which, like M. tuberculosis, is gram positive, and then in nonpathogenic mycobacteria. Previously, heat shock proteins of $M$. tuberculosis have been produced in high yield in E. coli intracellularly (14). However, these proteins are highly conserved and are present in both prokaryotes and eukaryotes. The extracellular proteins of $M$. tuberculosis studied here are evidently not highly conserved in bacteria; a homolog for only one of them was present in $M$. smegmatis. Our experience suggests the possibility that highlevel expression and especially secretion of relatively nonconserved Mycobacterium-specific proteins require a mycobacterial host. In this regard, it is interesting that the overall DNA homology between $M$. tuberculosis and $M$. smegmatis is only $\sim 15 \%$ (22).

The large amount of recombinant proteins expressed in $M$. smegmatis and released as soluble molecules into the extracellular milieu, the accuracy of leader peptide processing leading to recombinant proteins indistinguishable from their native counterparts, and the constitutive expression of recombinant proteins all argue for the feasibility of unraveling some of the components and mechanisms involving mycobacterial protein secretion in $M$. smegmatis. Since $M$. smegmatis is both rapidly growing and nonpathogenic, it may yield answers faster than slowly growing, pathogenic $M$. tuberculosis.

Although both M. tuberculosis and M. smegmatis express and secrete the four major extracellular proteins constitutively, they do so at different rates. By far the most abundant extracellular protein in M. tuberculosis cultures is the $30-\mathrm{kDa}$ protein, followed, in descending order of abundance, by the 32-, $16-$, and $23.5-\mathrm{kDa}$ proteins - the approximate ratio of production is $3: 2: 1.5: 1$. However, in M. smegmatis, the $23.5-\mathrm{kDa}$ protein is expressed at a rate at least twofold higher than that of the other three proteins. The approximate ratio of production is $1.5: 1.5: 1: 3$ for the $30-, 32-, 16-$, and $23.5-\mathrm{kDa}$ proteins, respectively. The basis for the observed differences is unknown.

In conclusion, our study makes possible the high-level production of recombinant $M$. tuberculosis major extracellular proteins by using nonpathogenic species of mycobacteria. The use of rapidly growing, nonpathogenic host species to produce these proteins avoids the exceptional biohazard of $M$. tuberculosis and effectively opens the door to mass production of these proteins for use in vaccines and as targets for new drug development.

\section{ACKNOWLEDGMENTS}

We are grateful to Sasa Maslesa-Galic and Barbara Jane Dillon for expert technical assistance. We thank Audree V. Fowler of the UCLA Protein Microsequencing Facility for performing N-terminal amino acid sequencing. We also thank Diane Wong and Bradford Gibson at UCSF for the mass spectrometry analyses of the native and recombinant forms of the 30-, 32-, 16-, and 23.5-kDa proteins.

This work was supported by grant AI-31338 from the National Institutes of Health. During the time this work was performed, B.-Y. Lee was supported by National Institutes of Health training grant AI07126.

\section{REFERENCES}

1. Amann, E., and J. Brosius. 1985. "ATG vectors" for regulated high-level expression of cloned genes in Escherichia coli. Gene 40:183-190.

2. Belisle, J. T., T. Sievert, K. Takayama, and G. S. Besra. 1995. Identification of a mycolyltransferase from Mycobacterium tuberculosis: extracellular release and characterization of its enzymatic activity, p. 212-216. In Program of the 30th Joint Conference on Tuberculosis and Leprosy 1995. U.S.-Japan Cooperative Medical Science Program, National Institute of Allergy and Infectious Diseases, National Institutes of Health, Ft. Collins, Colo.

3. Church, G. M., and W. Gilbert. 1984. Genomic sequencing. Proc. Natl. Acad. Sci. USA 81:1991-1995.

4. Das, A. 1993. Control of transcription termination by RNA-binding proteins Annu. Rev. Biochem. 62:893-930.

5. Garbe, T. R., J. Barathi, S. Barnini, Y. Zhang, C. Abou-Zeid, D. Tang, R. Mukherjee, and D. B. Young. 1994. Transformation of mycobacterial species using hygromycin resistance as selectable marker. Microbiology 140:133-138.

6. Hardy, K., S. Stahl, and H. Küpper. 1981. Production in B. subtilis of hepatitis B core antigen and a major antigen of foot and mouth disease virus. Nature 293:481-483.

7. Harth, G., D. L. Clemens, and M. A. Horwitz. 1994. Glutamine synthetase of Mycobacterium tuberculosis: extracellular release and characterization of its enzymatic activity. Proc. Natl. Acad. Sci. USA 91:9342-9346.

7a.Harth, G., and M. A. Horwitz. Unpublished data.

8. Harth, G., B.-Y. Lee, J. Wang, D. L. Clemens, and M. A. Horwitz. 1996. Novel insights into the genetics, biochemistry, and immunocytochemistry of the 30-kilodalton major extracellular protein of Mycobacterium tuberculosis. Infect. Immun. 64:3038-3047.

9. Hatfull, G. F., and G. J. Sarkis. 1993. DNA sequence, structure and gene expression of mycobacteriophage L5: phage system for mycobacterial genetics. Mol. Microbiol. 7:395-405.

10. Horwitz, M. A., B.-W. E. Lee, B. J. Dillon, and G. Harth. 1995. Protective immunity against tuberculosis induced by vaccination with major extracellular proteins of Mycobacterium tuberculosis. Proc. Natl. Acad. Sci. USA 92: $1530-1534$

11. Kremer, L., A. Baulard, J. Estaquier, J. Content, A. Capron, and C. Locht. 1995. Analysis of the Mycobacterium tuberculosis 85A antigen promoter region. J. Bacteriol. 177:642-653.

12. Lee, B.-Y., and M. A. Horwitz. 1995. Identification of macrophage and stressinduced proteins of Mycobacterium tuberculosis. J. Clin. Invest. 96:245-249.

13. McClure, W. R. 1985. Mechanism and control of transcription initiation in prokaryotes. Annu. Rev. Biochem. 54:171-204.

14. Mehlert, A., and D. B. Young. 1989. Biochemical and antigenic characterization of the Mycobacterium tuberculosis $71 \mathrm{kD}$ antigen, a member of the 70 kD heat-shock protein family. Mol. Microbiol. 3:125-130.

15. Oettinger, T., and A. B. Andersen. 1994. Cloning and B-cell-epitope mapping of MPT64 from Mycobacterium tuberculosis H37Rv. Infect. Immun. 62:20582064.

16. Pal, P. G., and M. A. Horwitz. 1992. Immunization with extracellular protein of Mycobacterium tuberculosis induces cell-mediated immune response and substantial protective immunity in a guinea pig model of pulmonary tuberculosis. Infect. Immun. 60:4781-4792.

17. Philipp, W. J., S. Poulet, K. Eiglmeier, L. Pascopella, V. Balasubramanian, B. Heym, S. Bergh, B. R. Bloom, W. R. Jacobs, Jr., and S. T. Cole. 1996. An integrated map of the genome of the tubercle bacillus, Mycobacterium tuberculosis H37Rv, and comparison with Mycobacterium leprae. Proc. Natl. Acad. Sci. USA 93:3132-3137.

18. Sanger, F., S. Nicklen, and A. R. Coulson. 1977. DNA sequencing with chain-terminating inhibitors. Proc. Natl. Acad. Sci. USA 74:5463-5467.

19. Sathyamoorthy, N., and K. Takayama. 1987. Purification and characterization of a novel mycolic acid exchange enzyme from Mycobacterium smegmatis. J. Biol. Chem. 262:13417-13423. 
20. Shine, J., and L. Dalgarno. 1974. The N-terminal sequence of Escherichia coli $16 \mathrm{~S}$ ribosomal RNA: complementarity to nonsense triplets and ribosome binding sites. Proc. Natl. Acad. Sci. USA 71:1342-1346.

21. Von Heijne, G. 1986. A new method for predicting signal sequence cleavage sites. Nucleic Acids Res. 14:4683-4690.

22. Wayne, L. G. 1984. Mycobacterial speciation, p. 25-65. In G. P. Kubica and L. G. Wayne (ed.), The mycobacteria. Marcel Dekker, Inc., New York, N.Y.

23. Williams, D. M., E. J. Duvall, and P. S. Lovett. 1981. Cloning restriction fragments that promote expression of a gene in Bacillus subtilis. J. Bacteriol. 146:1162-1165.

24. Yanisch-Perron, C., J. Vieira, and J. Messing. 1985. Improved M13 phage cloning vectors and host strains: nucleotide sequences of the M13mp18 and pUC19 vectors. Gene 33:103-119.

25. Zhang, Y., R. Lathigra, T. Garbe, D. Catty, and D. Young. 1991. Genetic analysis of superoxide dismutase, the 23 kilodalton antigen of Mycobacterium tuberculosis. Mol. Microbiol. 5:381-391.

Editor: P. J. Sansonetti 